Jurnal Geografi, Edukasi dan Lingkungan (JGEL) Vol. 4, No. 1, Januari 2020:25-31

P-ISSN: 2579-8499; E-ISSN: 2579-8510

Doi: https://doi.org/10.29405/jgel.v4i1.4261

Website: http://journal.uhamka.ac.id/index.php/jgel

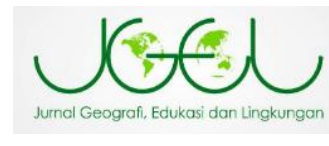

\title{
Prediksi Kebutuhan Air Bersih Desa Pinggirpapas Kecamatan Kalianget Kabupaten Sumenep Madura Pada Tahun 2029
}

\author{
Rahmat Nur Setiawan*, Tricahyono NH dan Siti Dahlia \\ Pendidikan Geografi, FKIP Universitas Muhammadiyah Prof. DR. Hamka, Jakarta \\ Timur, Indonesia
}

*E-mail: Nurrahmat7991@ gmail.com

Received: 07012020 / Accepted: 07012020 / Published online: 30012020

\begin{abstract}
ABSTRAK
Masalah penyediaan air bersih saat ini menjadi perhatian khusus karena sebagai pemenuhan kebutuhan pokok hidup manusia. Secara morfologi Desa Pinggirpapas merupakan daerah pesisir dan pantai yang kemiringan lerengnya berkisar 0-3\%, kondisi ini berakibat kepada kondisi air permukaan dan air tanah memiliki salinitas yang tinggi atau payau sampai asin. Tujuan Penelitian ini yaitu untuk mengetahui volume rata-rata kebutuhan air bersih perorang per hari, dan memprediksi volume kebutuhan air bersih seluruh penduduk di Desa Pinggirpapas pada tahun 2029. Metode penelitian merupakan penelitian survey dengan tujuan deskriptif dan dianalisi secara kualitatif. Populasi dalam penelitian yaitu Kepala Keluarga dengan jumlah 1.678 KK, dan sampel sebanyak 94 sampel dengan teknik proposional random sampling. Hasil penelitian menunjukkan bahwa rata-rata volume kebutuhan air bersih tiap Kepala Keluarga (KK) pada musim hujan sebesar 209,86 liter, dan 172,84 liter perhari pada musim kemarau. Rata-rata volume kebutuhan air bersih setiap orang (perkapita) perhari pada musim hujan sebesar 52,68 liter/orang perhari, sedangkan 43,99 liter/orang perhari pada musim kemarau. Prediksi volume kebutuhan air bersih seluruh penduduk Desa Pinggirpapas pada tahun 2029 musim hujan sebesar 362.754,48 liter/hari dan 302.915,14 liter/hari pada musim kemarau.
\end{abstract}

Kata Kunci: Prediksi Kebutuhan Air Bersih, Tahun 2029

\begin{abstract}
The problem of providing clean water is important because it is the fulfillment of the basic needs of human life. Morphologically, the village of Pinggirpapas is coastal area whose slope ranges from 0-3\%, this condition results in surface water conditions and groundwater has high salinity or brackish to salty. The aims of this study is to determine the average volume of clean water needs per person per day, and predict the volume of clean water needs of all residents in the village of Pinggirpapas in 2029. The research method is a survey research with descriptive purpose and qualitative analysis. The population in this study is the Head of the Family with a total of 1,678 households, and sample of respondens was 94 samples with a proportional random sampling technique. The results showed that the average volume of clean water needs per household (KK) in the rainy season was 209.86 liters, and 172.84 liters per day in the dry season. The average volume of clean water needs per person (per capita) per day in the rainy season is 52.68 liters / person per day, while 43.99 liters / person per day in the dry season.
\end{abstract}


Prediction of the volume of clean water needs of all residents of Pinggirpapas Village in 2029 is 362,754.48 liters / day in the rainy season and 302,915.14 liters / day in the dry season.

Keywords: Prediction of Clean Water Needs, 2029 Year

\section{PENDAHULUAN}

Indonesia merupakan salah satu negara yang kaya sumber daya air, ketersediaan sumber daya air mencapai 15.500 meter kubik perkapita pertahun. Angka ini masih jauh di atas rata-rata di dunia yang hanya 8.000 meter kubik per tahun. Meskipun begitu, Indonesia masih mengalami kelangkaan air bersih. Sekitar 119 juta rakyat Indonesia belum memiliki akses terhadap air bersih dari penyaluran air, usaha air secara komunitas serta sumur air (Qodriyatun, 2015). Menurut Wahyuni \& Junianto (2017), kebutuhan air bersih akan terus mengalami peningkatan dari tahun ke tahun akibat dari pertumbuhan penduduk yang sangat pesat.

Pada tahun 2003 telah terjadi kekeringan di 12 kabupaten di Jawa Barat, yaitu Indramayu, Tasikmalaya, Cirebon, Kuningan, Ciamis, Sumedang, Garut, Bandung, Cianjur, Sukabumi, Serang, dan Pandeglang. Sementara di Jawa Tengah enam kabupaten, yaitu Pati, Sragen, Boyolali, Wonogiri, Cilacap, dan Rembang. Di Jawa Timur ada dua kabupaten, yaitu Lamongan dan Tulungagung. Pulau Jawa, tergolong pulau yang kritis air (water stress area) setiap penduduk di Jawa hanya terpenuhi kebutuhan airnya dalam satu tahun sebesar $1.750 \mathrm{~m}^{3}$ per kapita. Standar titik kritis air karena pemenuhan kebutuhan airnya berada di bawah $2.000 \mathrm{~m}^{3}$ per kapita per tahun yang dipersyaratkan. Apabila dilihat dari komposisi dan beban kebutuhan yang harus disediakan, maka Pulau Jawa yang hanya $7 \%$ dari total luas daratan di Indonesia. Selain itu, Pulau Jawa dihuni $65 \%$ penduduk Indonesia yang membutuhkan paling sedikit sekitar 45$55 \%$ sumber daya air, sementara potensi sumber daya air di Pulau Jawa saat ini hanya tersedia $4,5 \%$ dari total potensi SDA (Mawardi, 2008).

Upaya pemenuhan kebutuhan air di Pulau Jawa telah ditempuh melalui pembangunan waduk besar dan sedang. Dari 14 waduk utama di Jawa, seluruhnya mengalami kondisi di bawah normal (pola kering) pada saat musim kemarau sehingga dilakukan penentuan prioritas pemanfaatan air waduk. Prioritas pertama diberikan untuk air minum, rumah tangga, dan perkotaan, baru kemudian prioritas kedua untuk irigasi, sedang prioritas ketiga untuk industri dan kebutuhan lainnya.

Pulau Madura merupakan salah satu kepulauan di Propinsi Jawa Timur. Secara administratif Pulau Madura terbagi dalam empat Kabupaten, dari Barat ke Timur yaitu Kabupaten Bangkalan, Sampang, Pamengkasan dan Sumenep. Pulau Madura memiliki dua musim, yaitu musim "Timur" atau musim Kemarau dan musim "Barat" atau musim Hujan. Curah hujan memiliki intensitas yang tidak sama. Di lereng-lereng yang tinggi, curah hujan cukup tinggi, sedangkan di lereng-lereng yang rendah, curah hujan sangat sedikit. Hal ini disebabkan curah hujan yang sedikit itu terletak di daerah yang rendah, sehingga membuat Madura terlihat kurang memiliki tanah yang subur dan permasalahan terhadap air bersih (Azhar, 2016).

Desa Pinggirpapas terletak di Kecamatan Kalianget Kabupaten Sumenep Madura Provinsi Jawa Timur. Berdasarkan Morfologinya Desa Pinggirpaps merupakan daerah pesisir dan pantai yang kemiringan lerengnya 0-3\%, sehingga kondisi ini berakibat kepada air permukaan dan air tanahnya memiliki salinitas yang 
tinggi atau payau sampai asin. Desa Pinggirpapas memiliki 3 sumber Air yakni, air tanah, air sungai dan air rawa. Air tanah tidak bisa digunakan karena adanya rasa asin dan memiliki kadar Salinitas yang tinggi. Air Sungai dan Air Rawa di Desa Pingggirpapas tersebut tercemar oleh sampah domestik dan tempat pembuangan tinja manusia. Akibatnya tidak dapat dimanfaatkan sebagai sumber daya air bersih. Oleh karena itu, sumber daya air bersih di Desa pinggirpapas hanya berasal dari PDAM.

Kebutuhan air bersih mengalami peningkatan akibat meningkatnya jumlah penduduk dari tahun ke tahun dan penggunaanya, disisi lain sumber air bersih di Desa Pinggirpapas terbatas pada PDAM. Hal tersebut dapat menimbulkan permasalahan kekurangan air bersih, terutama dimusim kemarau. Karena ketika masuk musim kemarau sumber air bersih sangat sulit didapatkan. Berdasarkan hal tersebut, tujuan Penelitian ini yaitu untuk mengetahui volume rata-rata kebutuhan air bersih perorang per hari, dan memprediksi volume kebutuhan air bersih seluruh penduduk di Desa Pinggirpapas pada tahun 2029.

\section{METODE PENELITIAN \\ Waktu dan Lokasi Penelitian}

Penelitian ini dilakukan pada bulan Agustus 2019. Lokasi Penelitian ini di Desa Pinggirpapas Kecamatan Kalianget Kabupaten Sumenep Madura Provinsi Jawa Timur. Letak Astronomis Desa Pinggirpapas yaitu $07^{\circ} \quad 03^{\prime} \quad 28,7^{\prime \prime}$ LS sampai $07^{\circ} 04^{\prime} 8^{\prime \prime}$ LS dan $113^{\circ} 51^{\prime}$ '20,8" BT sampai $113^{\circ}$ 52' 55,3” BT. Wilayah penelitian merupakan area pesisir, sehingga mayoritas pemanfatan lahan merupakan area tambak. Lokasi penelitian disajikan pada Gambar 1.

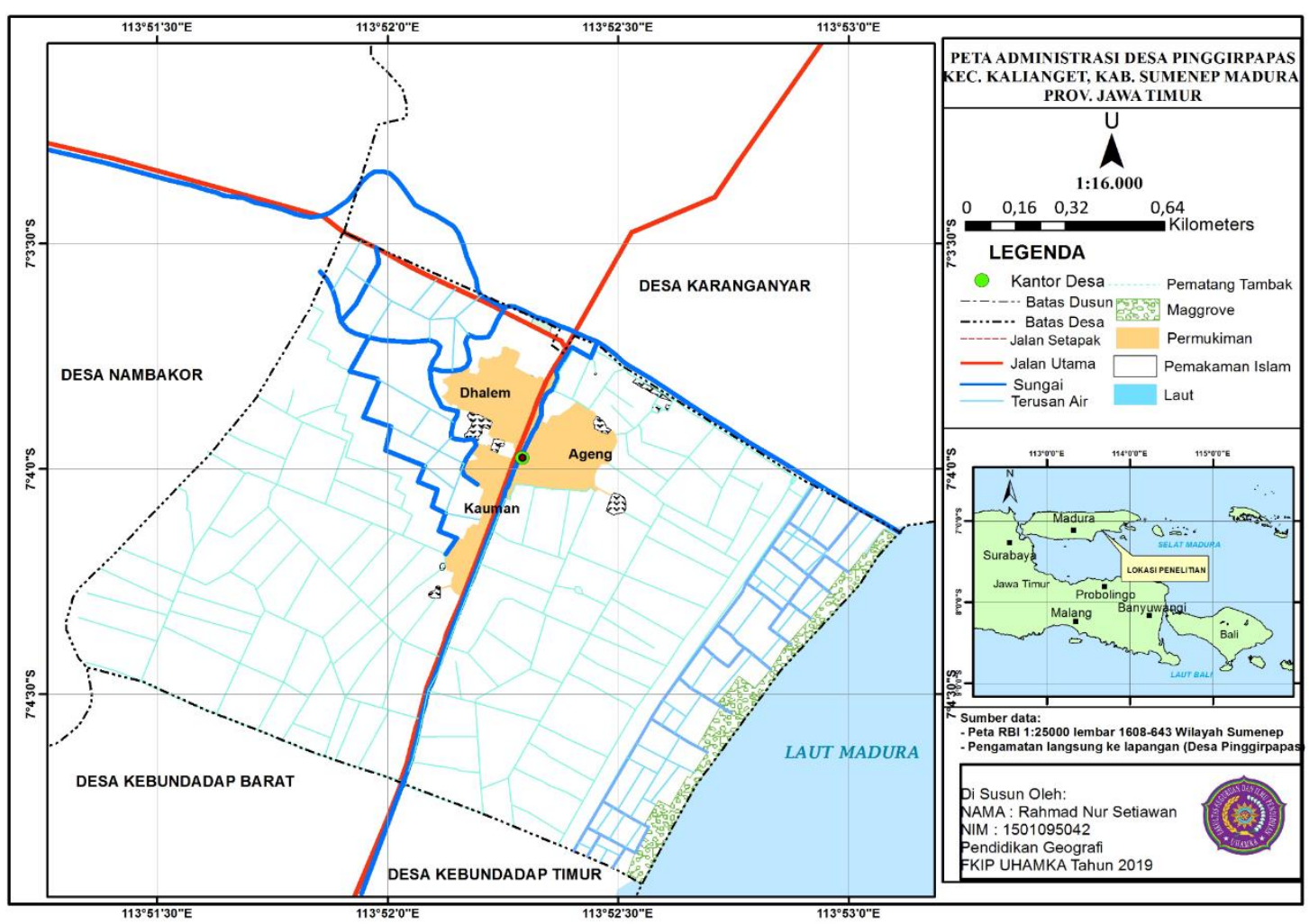

Gambar 1. Lokasi Penelitian 


\section{Alat dan Bahan}

Alat dan bahan yang digunakan dalam penelitian ini beserta fungsinya disajikan pada Tabel 1 .

Tabel 1. Alat dan Bahan Penelitian

\begin{tabular}{cll} 
No & \multicolumn{1}{c}{$\begin{array}{c}\text { Alat dan } \\
\text { Bahan }\end{array}$} & \multicolumn{1}{c}{ Fungsi } \\
\hline $\mathbf{1}$ & GPS Garmin & $\begin{array}{l}\text { Merekam titik } \\
\text { koordinat }\end{array}$ \\
\hline $\mathbf{2}$ & $\begin{array}{l}\text { Perangkat } \\
\text { Lunak Arc-Gis } \\
10.6\end{array}$ & Analisis spasial \\
\hline $\mathbf{3}$ & $\begin{array}{l}\text { Kamera } \\
\text { DigitalCanon } \\
\text { A2300 }\end{array}$ & Dokumentasi \\
\hline $\mathbf{4}$ & Kuesioner & $\begin{array}{l}\text { Mengumpulkan } \\
\text { data primer }\end{array}$ \\
\hline $\mathbf{5}$ & $\begin{array}{l}\text { Perangkat lunak } \\
\text { DNRGPS }\end{array}$ & $\begin{array}{l}\text { Transfer data } \\
\text { hasil tracking } \\
\text { GPS }\end{array}$ \\
\hline $\mathbf{6}$ & Peta Rupa & $\begin{array}{l}\text { Administrasi } \\
\text { Bilayah }\end{array}$ \\
& Bumi & \begin{tabular}{l} 
Penelitian \\
\hline
\end{tabular} \\
\hline
\end{tabular}

\section{Jenis Penelitian}

Jenis penelitian ini merupakan penelitian penelitian survey dengan tujuan deskriptif dan dianalisis secara kualitatif. Penelitian survey yaitu peneliti melakukan survey terkait kebutuhan air bersih perorang penduduk Desa Pingirpapas menggunakan kuesioner. Hasil temuan dilakukan tabulasi, sehingga dapat di deskripsikan terkait data kebutuhan air bersih penduduk wilayah penelitian.

\section{Metode pengumpulan, pengolahan, dan Analisis Data}

Metode pengumpulan data dalam penelitian ini terdiri atas data primer dan data sekunder. Metode pengumpulan data berupa wawancara, dokumentasi, dan observasi. Data primer yang dikumpulkan dalam penelitian yaitu melalui survei lapangan menggunakan kuesioner untuk memperoleh data kebutuhan air bersih setiap Kepala Keluarga. Kisi-kisi instrument disajikan pada Tabel 2. Data
Sekunder dalam penelitian ini berupa data Peta Rupabumi, dan Data monografi wilayah penelitian.

Tabel 2. Kisi-kisi instrument

\begin{tabular}{lc}
\multicolumn{1}{c}{ Indikator } & Nomor Butir \\
\hline $\begin{array}{l}\text { Identitas } \\
\text { Respoden }\end{array}$ & $1-11$ \\
\hline $\begin{array}{l}\text { sumber air pada } \\
\text { musim hujan dan } \\
\text { kemarau }\end{array}$ & $12-14$ \\
\hline $\begin{array}{l}\text { Kebutuhan air dan } \\
\text { volume air bersih }\end{array}$ & 15,17 \\
pada musim hujan & \\
$\&$ kemarau & \\
\hline $\begin{array}{l}\text { Kecukupan air } \\
\text { bersih pada musim } \\
\text { kemarau dari } \\
\text { PDAM }\end{array}$ & 18 \\
\hline
\end{tabular}

Pengolahan data yang dilakukan dalam penelitian ini yaitu menghitung proyeksi penduduk, menghitung rata-rata kebutuhan air bersih perorang dalam satu hari, menghitung rata-rata besarnya kebutuhan air bersih perorang dalam satu keluarga perhari (liter/orang, perhari), dan menghitung prediksi besarnya kebutuhan air bersih pada tahun 2029 .

Menurut Mantra, (2009) untuk menghitung rata-rata besarnya kebutuhan air bersih perorang dalam satu keluarga perhari (liter/orang, perhari) dihitung dengan Persamaan 1 dan menghitung ratarata kebutuhan air bersih perorang dalam satu hari menggunakan Persamaan 2 :

$$
\mathrm{B}=\mathrm{K} / \mathrm{n} \text {........Persamaan } 1
$$

Keterangan:

B: Rata-rata kebutuhan air bersih perorang perhari dalam satu keluarga (liter/orang, perhari)

K: Kebutuhan air bersih dalam satu kepala keluarga perhari (liter, perorang, perhari).

n: Banyaknya orang dalam satu kepala keluarga.

$$
\overline{\mathrm{B}}=\frac{\sum \mathrm{B}}{\mathrm{KK}} \ldots \text { Persamaan } 2
$$


Keterangan:

$\overline{\mathrm{B}} \quad$ Rata-rata kebutuhan air bersih perorang perhari pada penduduk di Desa Pinggirpapas (liter/orang perhari)

$\sum$ B Jumlah rata-rata konsumsi air bersih

$\sum \mathrm{B}$ perorang perhari (liter/orang perhari)

KK Banyaknya Kepala Keluarga

Menurut Adioetomo dan Samosir, (2010) untuk menghitung proyeksi penduduk dilakukan dengan Persamaan 3, sedangkan untuk menghitung prediksi besarnya kebutuhan air bersih pada tahun 2029 dilakukan dengan Persamaan 4:

$$
\text { Pn }=\text { Po }(1+\mathrm{rn}) \ldots \ldots \ldots \text {..Persamaan } 3
$$

\section{Keterangan: \\ Pn jumlah penduduk pada tahun $\mathrm{n}$ \\ Po jumlah penduduk pada tahun awal (dasar) \\ r angka pertumbuhan penduduk \\ $\mathrm{n}$ periode waktu antara tahun dasar dan tahun $\mathrm{n}$ (dalam tahun)}

$$
\mathrm{PB}=\mathrm{B}^{-} \mathrm{x} \text { Pt.........Persamaan } 4
$$

Keterangan:

PB besarnya kebutuhan air bersih penduduk (liter/hari)

B Rata-rata kebutuhan air bersih perorang perhari penduduk Desa Pinggirpapas (liter, orang, perhari)

Pt Prediksi jumlah penduduk pada tahun 2029

Metode analisis data dalam penelitian ini menggunakan analisis deskriptif yaitu mendeskripsikan data hasil perhitungan proyeksi penduduk, kebutuhan air bersih perorang dan Kepala Keluarga, sehingga mendeskripsikan prediksi kebutuhan air bersih pada Tahun 2029.

\section{HASIL DAN PEMBAHASAN}

1. Volume kebutuhan Air bersih Penduduk Desa Pinggirpapas

Kebutuhan air bersih penduduk wilayah penelitian dikelompokan menjadi dua yaitu kebutuhan air bersih penduduk dalam satu Kepala Keluarga perhari dan kebutuhan air bersih perorang perhari. Hasil penelitian menunjukkan bahwa ratarata volume kebutuhan air bersih tiap Kepala Keluarga (KK) pada musim hujan sebesar 209,86 liter perhari, dan pada musim kemarau rata-rata volume kebutuhan air bersih tiap kepala keluarga (KK) sebesar 172,84 liter perhari. Rincian data kebutuhan air bersih tiap Kepala Keluarga (KK) disajikan pada Tabel 3.

Tabel 3. Kebutuhan Air Bersih Penduduk Wilayah Penelitian Berdasarkan Kepala Keluarga

\begin{tabular}{|c|l|c|c|}
\hline No & \multirow{2}{*}{$\begin{array}{c}\text { Jenis } \\
\text { Penggunaan }\end{array}$} & \multicolumn{2}{|c|}{$\begin{array}{c}\text { Kebutuhan Air } \\
\text { (Liter) }\end{array}$} \\
\cline { 3 - 4 } & & Hujan & Kemarau \\
\hline 1 & memasak & 8,32 & 7,22 \\
\hline 2 & minum & 7,36 & 9,65 \\
\hline 3 & mandi & 31,90 & 27,18 \\
\hline 4 & $\begin{array}{l}\text { mencuci } \\
\text { pakaian }\end{array}$ & 49,23 & 38,87 \\
\hline 5 & buang air & 24,03 & 22,07 \\
\hline 6 & mencuci alat & 17,07 & 14,10 \\
\hline 7 & dapur & 16,94 & 11,87 \\
\hline 8 & mencuci lantai & 27,18 & 25,63 \\
\hline 9 & lain-lain & 23,98 & 16,24 \\
\hline
\end{tabular}

Berdasarkan Tabel 3, penggunaan air terbesar masyarakat wilayah penelitian pada musim hujan dan kemarau berdasarkan Kepala Keluarga yaitu untuk mencuci pakaian 49,23 liter perhari pada musim hujan dan 38,87 liter perhari pada musim kemarau. Penggunaan air terkecil pada musim kemarau yaitu untuk kebutuhan minum 7,36 liter perhari, sedangkan pada musim kemarau 7,22 liter perhari untuk memasak. Penggunaan air terbesar pada musim hujan dan kemarau terdapat dijenis penggunaan mencuci pakaian, dikarenkan aktivitas warga lebih banyak diluar ruangan. Untuk penggunaan air terkecil pada musim hujan terdapat pada jenis penggunaan air yaitu minum, hal ini disebabkan karena pada musim 
hujan kelembaban udara cukup tinggi, sehingga warga tidak mudah terkena dehidrasi.

Berdaskan kebutuhan rata-rata volume kebutuhan air bersih setiap orang (perkapita) perhari di wilayah penelitian pada musim hujan yaitu sebesar 52,68 liter/orang perhari. Rata-rata volume kebutuhan air bersih setiap orang (perkapita) perhari pada musim kemarau, yaitu sebesar 43,99 liter/orang perhari. Rincian data disajikan pada Tabel 4.

Tabel 4. Kebutuhan Air Bersih Penduduk Wilayah Penelitian Berdasarkan Perorangan

\begin{tabular}{|c|l|c|c|}
\hline \multirow{2}{*}{ No } & \multirow{2}{*}{$\begin{array}{c}\text { Jenis } \\
\end{array}$} & Penggunaan & \multicolumn{2}{|c|}{ Kebutuhan Air (Liter) } \\
\cline { 3 - 4 } & memasak & 2,13 & Kemarau \\
\hline 2 & minum & 1,88 & 2,83 \\
\hline 3 & mandi & 8,21 & 6,89 \\
\hline 4 & $\begin{array}{l}\text { mencuci } \\
\text { pakaian }\end{array}$ & 12,62 & 9,93 \\
\hline 5 & buang air & 6,20 & 5,60 \\
\hline 6 & $\begin{array}{l}\text { mencuci alat } \\
\text { dapur }\end{array}$ & 4,35 & 3,59 \\
\hline 7 & $\begin{array}{l}\text { mencuci } \\
\text { lantai }\end{array}$ & 4,28 & 3,00 \\
\hline 8 & wudhu & 6,95 & 6,54 \\
\hline 9 & lain-lain & 6,08 & 4,10 \\
\hline Jumlah & $\mathbf{5 2 , 6 8}$ & $\mathbf{4 3 , 9 9}$ \\
\hline
\end{tabular}

Berdasarkan Tabel 4 penggunaan air terbesar pada musim hujan dan kemarau menurut perorangan yaitu mencuci pakaian, 12,62 liter perhari pada musim hujan dan 9,93 liter perhari pada musim kemarau. Penggunaan air terkecil pada musim hujan yaitu 1,88 liter perhari untuk minum, sedangkan pada musim kemarau yaitu untuk memasak 1,83 liter perhari. Penggunaan air terbesar pada kedua musim terdapat dijenis penggunaan mencuci pakaian, ini dikarenkan aktivitas warga lebih banyak diluar ruangan, yaitu sebagai nelayan dan petani tambak. Penggunaan air terkecil terdapat pada jenis penggunaan air yaitu minum, ini disebabkan karena pada musim hujan, kelembaban udara cukup tinggi, sehingga warga tidak mudah terkena dehidrasi. Jadi kebutuhan air nya kecil atau sedikit. Selain itu, penggunaan air terendah pada musim kemarau yaitu memasak. Hal ini dapat di identifikasi bahwa untuk kepentingan memasak masyarakat tidak banyak membutuhkan air.

\section{Prediksi besarnya volume kebutuhan air bersih penduduk di Desa Pinggirpapas pada tahun 2029.}

Perhitungan kebutuhan dan pelayanan air bersih harus memperhitungkan jumlah penduduk di wilayah penelitian (Ardiansyah, Juwono, \& Ismoyo, 2012). Hasil prediksi banyaknya penduduk Desa Pinggirpapas pada Tahun 2029 sebesar 6.876 orang. Berdasarkan hal tersebut, prediksi volume kebutuhan air bersih penduduk wilayah penelitian pada Tahun 2029 pada musim hujan yaitu sebesar 362.754,5 liter/hari, sedangkan pada musim kemarau sebesar 302.915,1 liter/hari. Volume kebutuhan air bersih penduduk dalam satu tahun sebesar 132.405.385 liter/tahun pada musim hujan, dan 110.564.026,1 liter/tahun pada musim kemarau. Rincian prediksi kebutuhan air pada musim hujan dan kemarau pada Tahun 2029 disajikan pada Tabel 5.

Tabel 5. Prediksi Kebutuhan Air Bersih Penduduk Wilayah Penelitian Pada Tahun 2029

\begin{tabular}{|c|l|r|r|}
\hline No & \multirow{2}{*}{$\begin{array}{c}\text { Jenis } \\
\text { Penggun } \\
\text { aan }\end{array}$} & \multicolumn{1}{l|}{ Volume Air (liter/hari) } \\
\cline { 3 - 4 } & memasak & $14.510,18$ & $12.116,604$ \\
\hline 2 & minum & $14.510,18$ & $18.174,906$ \\
\hline 3 & mandi & $54.413,175$ & $48.466,416$ \\
\hline 4 & $\begin{array}{l}\text { mencuci } \\
\text { pakaian }\end{array}$ & $87.061,08$ & $66.641,322$ \\
\hline 5 & buang air & $43.530,54$ & $39.378,963$ \\
\hline 6 & $\begin{array}{l}\text { mencuci } \\
\text { alat } \\
\text { dapur }\end{array}$ & $32.647,905$ & $24.233,208$ \\
\hline 7 & $\begin{array}{l}\text { mencuci } \\
\text { lantai }\end{array}$ & $29.020,36$ & $21.204,057$ \\
\hline 8 & wudhu & $47.158,085$ & $45.437,265$ \\
\hline
\end{tabular}




\begin{tabular}{|l|l|c|r|}
\hline 9 & lain-lain & $39.902,995$ & $27.262,359$ \\
\hline Jumlah & $362.754,5$ & $362.754,5$ \\
\hline
\end{tabular}

Berdasarkan Tabel 5 prediksi penggunaan air terbesar pada musim hujan dan kemarau yaitu untuk mencuci pakaian, yaitu $87.061,08$ liter/hari dan $48.466,416$ liter/hari. Kebutuhan air pada musim kemarau dan hujan tinggi untuk mencuci, karena proses mencuci membutuhkan jumlah air yang banyak untuk proses merendam dan membilas baju.

Volume penggunaan air terkecil yaitu untuk kebutuhan memasak dan minum. Hal ini di karenakan proses memasak tidak membutuhkan jumlah air yang banyak. Kebutuhan penduduk untuk minum merupakan terendah setelah memasak dibandingkan dengan kebutuhan penggunaan air yang lainnya. Padahal kondisi suhu wilayah penelitian dengan tingkat kelembaban rendah, sehingga seharusnya kebtuuhan penduduk terkait air minum tinggi.

\section{KESIMPULAN.}

Rata-rata volume kebutuhan air bersih tiap kepala keluarga $(\mathrm{KK})$ pada musim hujan sebesar 209,86 liter, dan kepala keluarga (KK) pada musim kemarau 172,84 liter perhari. Rata-rata volume kebutuhan air bersih setiap orang (perkapita) perhari pada musim hujan sebesar 52,68 liter/orang perhari, sedangkan pada musim kemarau sebesar 43,99 liter/orang perhari. Prediksi volume kebutuhan air bersih seluruh penduduk Desa Pinggirpapas pada tahun 2029 musim hujan sebesar 362.754,48 liter/hari dan pada musim kemarau sebesar 302.915,14 liter/hari.

\section{DAFTAR PUSTAKA}

Adioetomo, S. M. \& Samosir, O. B. (2013). Dasar-Dasar Demografi. Jakarta. Salemba Empat dan Lembaga Demografi Fakultas Ekonomi Universitas Indonesia.
Ardiyansyah, Juwono, P.T., \& Ismoyo, M.J. (2012). Analisa Kinerja Sistem Distribusi Air Bersih pada PDAM di Kota Ternate. Jurnal Teknik Pengairan, 3 (2), 211-220.

Azhar, N. I. (2016). Air Sebagai Bentuk Legenda Masyarakat Madura Barat. Prosding Seminar Nasional Merawat Madura Melalui Modal Budaya, halaman 314-329.

Mantra, I. D. (2009). Demografi Umum. Yogyakarta

Mawardi, I. (2008). Upaya meningkatkan daya dukung Sumberdaya Air di Pulau Jawa. Jurnal Teknik Lingkungan, 9 (1).

Qodriyatun, S. N. (2015). Penyediaan air bersih di Indonesia. P3DI Setjen DPR RI dan Azza Grafika. Jakarta.

Wahyuni, A. \& Junianto. (2017). Analisa kebutuhan air bersih pada kota batam pada tahun 2025. TAPAK, 6 (2). 